\title{
Understanding and Improving Quality of Care in the Context of Depressed Elderly Persons Living in Norway
}

\author{
Elisabeth Severinsson, Anne Lise Holm \\ The Centre for Women's, Family and Child Health, Faculty of Health Sciences, Buskerud \& Vestfold University \\ College, Kongsberg, Norway \\ Email: elisabeth.severinsson@hbv.no, anne.holm@hsh.no
}

Received 24 August 2014; revised 9 October 2014; accepted 5 November 2014

Academic Editor: Solina Richter, University of Alberta, Canada

Copyright (C) 2014 by authors and Scientific Research Publishing Inc.

This work is licensed under the Creative Commons Attribution International License (CC BY).

http://creativecommons.org/licenses/by/4.0/

(c) (i) Open Access

\begin{abstract}
Effective leadership plays an important role in safe patient care. The aim of this paper was to understand and improve the implementation outcomes identified by empirical studies based on Proctors et al.'s key concepts, acceptability appropriateness, feasibility and fidelity, and to propose recommendations for further research. Methods: An interdisciplinary approach using mixed methods. Results: A total of twenty papers based on data from this interdisciplinary study have been published. Overall, our published empirical studies revealed that the CCM intervention had positive results due to staff members' engagement to improve care, their awareness of the need for collaboration and willingness to assume responsibility for patient care. From the perspective of the depressed elderly persons the results of the research project indicated their need for support to increase self-management. In conclusion, an improved understanding of the implementation outcomes will have an impact on best practice for depressed elderly persons and dissemination purposes. Quality management and highly action-oriented involvement are necessary in implementation research. These will also affect the professional development of interdisciplinary teams as well as constitute a basis for further research on understanding and improving the care of depressed elderly individuals.
\end{abstract}

\section{Keywords}

Depression, Effective Leadership, Elderly, Implementation 


\section{Introduction}

One of the greatest challenges faced by healthcare systems is the increasing burden of chronic diseases [1]. Among the most common are hypertension, depression, diabetes and asthma [2]. Mental health promotion includes research on the burden of depression and other mental health problems. The WHO [2]-[5] guidelines for research on depression, a leading chronic illness worldwide and the third most common reason for primary care consultations were adopted. Several recent studies have explored the phenomenon of depression among older persons [6]-[8].

\subsection{Background}

One criterion for funding from the Research Council of Norway's Programme on Health and Care Services is that the research must relate to organising, managing, financing and delivering high-quality health and care services as well as providing a higher level of safety for the individual patient. We investigated patients who utilized the healthcare services. Another criterion for funding is thematic priority areas such as chronic conditions and illnesses. Thus, people with long-term disabilities and the elderly are the groups that are focused upon in this research project. A further criterion is to strengthen cooperation between different healthcare services and outline which is necessary to ensure the delivery of comprehensive and high-quality care. The long-term benefit of interdisciplinary research is a better understanding of the importance of daily activities and user participation for health and well-being [9].

The present project was intended to enhance understanding of health service users. The ultimate outcome was to increase the opportunities for patients to participate in their care, strengthen their autonomy and well-being and increase opportunities for shared decision making, in addition to strengthening their self-management. Another intended outcome of this research was that increasing the ability of healthcare professionals to adopt new knowledge in specific situations would deepen their professional competence.

\subsection{The Chronic Disease Management Project}

The Chronic Disease Management project was developed, implemented and evaluated at Buskerud \& Vestfold University College in 2010 by an interdisciplinary collaborative group of renowned experts in the field of healthcare sciences comprising five researchers representing four disciplines. The primary objective of this four-year project was to examine whether the implementation of the Chronic Care Model (CCM) for depressed elderly persons in the community could positively improve their mental state. The project involved three integrated phases (i.e. exploring, implementing and evaluating) linked to each other in terms of conceptual definitions, the theoretical model, methodological development, empirical qualitative analysis, theoretical reviews, updating of reviews and dissemination of results which enhanced the knowledge base. Three specific objectives were formulated. This paper describes the outcomes of the integrated research process pertaining to three specific objectives: to identify depressed elderly persons' subjective experiences of the healthcare system; to implement the CCM model in interdisciplinary teams in the healthcare system; to evaluate the quality of care provided in relation to the determinants inherent in the CCM.

The CCM served as a frame of reference for interventions at both individual and structural level [2] [10] [11]. The model is a guide for the development of effective chronic care and has been adopted by the WHO [4] to support policy change. The CCM is based on six interrelated components that are essential for providing quality care to patients with chronic illness: self-management support (helping the patient and her/his family to acquire the skills and confidence to manage everyday life); clinical information systems (how to manage information and use clinical care); delivery system redesign (creating teams with clear responsibility); decision support (providing optimal care at the right time); the healthcare organization; community-based resources (e.g. exercise programmes, senior citizen centres and self-help groups). The research questions addressed were: what are the patient's subjective experiences of her/his mental health problems; what are the patient's and family members' subjective experiences of the healthcare services; how can chronic disease management be improved for persons with depression; how can strategies to support patient self-management be improved; what are the patients' pathways through the healthcare system?

\subsection{Problem Statement}

The rationale for this paper was three-fold: 1) to increase understanding of the depressed elderly patients' expe- 
riences of their condition and participation in their care in order to increase their autonomy and well-being; 2) to identify and narrow the gaps between healthcare services, the hospital and community systems resources; 3 ) to evaluate whether implementation of the CCM's components enhanced the care. In this research we adopted an implementation approach to explore ill-health and changes in the healthcare services among depressed elderly care individuals [12]. We defined implementation as a specific set of strategies designed to put activities or a programme of known dimensions into practice [13]. Therefore, the outcomes of the implementation research, i.e. the improvements in patient well-being, are examined at the individual level using the concepts, satisfaction, function and symptomatology [14]. In addition, six quality improvements of service outcomes, i.e. efficiency, safety, effectiveness, equity, patient-centeredness and timeliness, are used [15] [16].

\subsection{Aim}

The aim of this paper was to understand and improve the implementation outcomes identified by empirical studies based on Proctors et al.'s [14] [17] key concepts, acceptability appropriateness, feasibility and fidelity, and to propose recommendations for further research.

\section{Methodology}

\subsection{Synthesizing Empirical Qualitative Research and Literature Review}

By combining qualitative methodological strategies in an integrative way with empirical studies, literature reviews and updating reviews of the core concepts we obtained a deeper understanding of the evidence. This means that the conceptually linked research questions provided updated scientific evidence of concepts such as synthesis of barriers to and facilitators of the successful implementation of the CCM [18], effective nursing leadership [19] and depressed elderly persons' perceptions of health, ill-health and community healthcare needs [9]. The reviews expanded upon previous findings and highlighted ongoing research on questions that need to be addressed to advance this field of study. The theoretical understanding was enhanced by updating state-of-the art reviews. The initial results provided useful evidence for developing future studies. In particular, very rich data on a wide range of experiences of mental illness were reported. The subjective dimension of experiences of illhealth was captured by interviews and is highlighted under the heading results and interpretation.

The research group held regular meetings including discussions on the design, definition of key terms, analysis and interpretation of the results. As far as the methodology is concerned, valuable positive and negative experiences were gained during course the Chronic Disease Management project. However, negative aspects were successfully overcome by intensive teamwork, dialogues about how to improve communication, bridging disciplinary values and attitudes as well as cultural aspects. In addition, methodological problems arose, for example how to analyse the text more deeply and why it is important to not reduce the meaning of the transcribed interview text.

\subsection{Participants}

Twenty-nine persons, diagnosed with depressive or mood disorder, were recruited by nurse managers in the communities and mental healthcare services on the West Coast and in the Eastern part of Norway. Other inclusion criteria were being able to understand and speak Norwegian, receiving formal treatment and support from primary community healthcare during the previous six months, aged over 60 years and resident in a community in Norway. The sample comprised 26 women and three men. Their mean age was 66 years and the range was 60 - 91 years. During the implementation phase two teams of healthcare professionals were involved. Team A consisted of four community psychiatric nurses; three of them were registered mental health nurses, and who cared for persons diagnosed as suffering from depression. Three of them comprised registered mental health nurses. Team B was represented by an experienced nurse from a psychogeriatric hospital.

\subsection{Ethical Considerations}

The project, which was carried out in accordance with guidelines in the Declaration of Helsinki [20], fulfils all legal and ethical requirements. Application for Phases I, II and III was made to the appropriate ethical review authority in Norway and the study was approved by the Regional Ethics Committee of Western Norway (Num- 
ber 2010/2242). During the various data collection phases all participants received both oral and written information about the aim of the study. They were also informed about the voluntary nature of participation and the possibility to withdraw at any stage before publication of the results. Any content that could allow the respondents to be identified was removed prior to the analysis and they were guaranteed confidentiality. The researchers who conducted the interviews have been trained to deal with and respond to sensitive issues [21]. The researchers are responsible for the participants' safety and security in the interview situation. Referral to mental healthcare was available if required. All patients were invited to contact a named professional if they felt in any way upset after the interviews.

\section{Results and Interpretation}

The evidence from the three stages; exploring, implementing and evaluating is described and interpreted based on the quality implementation framework of critical steps in the research process outline by Proctor et al. ([14], p. 3, 8-9) and Berwick ([16], p. 83-86, Table 1). A total of twenty papers based on data from this interdisciplinary study have been published.

Overall, our published empirical studies revealed that the CCM intervention had positive results. In order to understand the effectiveness of the CCM from patient and staff's perspectives, we developed parallel literature reviews of core concepts at all stages of the research process. After the theoretical explorative literature studies we synthesized and evaluated the sustainability of the implementation outcomes using Proctor et al.'s [14] conceptual framework; acceptability, appropriateness, feasibility, and fidelity (Table 1). Finally, we evaluated staff members' engagement, barriers to and facilitators of improved care as well as their awareness of the need for collaboration and willingness to assume responsibility for patient safety. From the perspective of the depressed elderly persons the results of the research project indicated their need for support to increase self-management.

Table 1. Implementation outcomes; acceptability appropriateness, feasibility, and fidelity (Proctor, et al. (2010), p. 3, 8-9) evaluated in relation to the six improvement dimensions of healthcare performance (Berwick (2002), p. 83-86) and patient outcome variables based on the implementation of the Chronic Care Model (CCM) in the context of depressed elderly persons.

\begin{tabular}{|c|c|c|}
\hline Implementation Outcomes & Service Outcomes & Patient Outcomes \\
\hline $\begin{array}{l}\text { Acceptability, i.e. the perceptions among } \\
\text { stakeholders that a given treatment, } \\
\text { service, practice, or } \\
\text { innovation }(\mathrm{CCM}) \text { is acceptable or } \\
\text { satisfactory. }\end{array}$ & $\begin{array}{l}\text { Effectiveness of the CCM } \\
\text { Patient perceptions-interviews } \\
\text { The perceptions of the healthcare } \\
\text { professionals who were involved in } \\
\text { education } \\
\text { Patient-centeredness } \\
\text { Timeliness of care }\end{array}$ & $\begin{array}{l}\text { Improved self-management } \\
\text { Satisfaction with the continuity of } \\
\text { relationships } \\
\text { Participating in informed decisions about } \\
\text { treatment } \\
\text { Decision-making based on evidence } \\
\text { Physical health problems } \\
\text { Responsibility for coordination and } \\
\text { collaboration }\end{array}$ \\
\hline $\begin{array}{l}\text { Appropriateness, i.e. the perceived fit, } \\
\text { relevance, or compatibility of the } \\
\text { innovation for a given setting, provider, or } \\
\text { consumer and/or perceived fit of the } \\
\text { innovation to address a particular issue or } \\
\text { problem. }\end{array}$ & $\begin{array}{l}\text { Patients' perceived quality of } \\
\text { life_interviews } \\
\text { Healthcare professionals' perceived } \\
\text { efficiency across disciplines and roles } \\
\text { Knowledge sharing }\end{array}$ & $\begin{array}{l}\text { Living with stigma } \\
\text { Afraid of being helpless } \\
\text { Dependent on others } \\
\text { Isolation and hopelessness } \\
\text { Lack of access to care }\end{array}$ \\
\hline $\begin{array}{l}\text { Feasibility, i.e. the extent to which a new } \\
\text { treatment, or an innovation, can be } \\
\text { successfully used or carried out within a } \\
\text { given setting. }\end{array}$ & $\begin{array}{l}\text { Analysis of feasibility was discussed before } \\
\text { the start of the implementation } \\
\text { Poor recruitment in terms of gender equality } \\
\text { Ensuring safety as a property of the system } \\
\text { Staff group/team learning/education } \\
\text { Supervision }\end{array}$ & $\begin{array}{l}\text { Guiding principles for design and } \\
\text { feasibility } \\
\text { Cooperation to ensure safety } \\
\text { Effective teams and team work }\end{array}$ \\
\hline $\begin{array}{l}\text { Fidelity, i.e. the degree to which the CCM } \\
\text { intervention was implemented as set out in } \\
\text { the original protocol. }\end{array}$ & $\begin{array}{l}\text { Group meeting, seminar and international } \\
\text { conferences } \\
\text { Ethical considerations including no waste of } \\
\text { patient time } \\
\text { State-of-the art information/evidence }\end{array}$ & $\begin{array}{l}\text { Ensuring evidence-based knowledge to } \\
\text { judge the research process and outcomes }\end{array}$ \\
\hline
\end{tabular}




\subsection{Phase 1: Explorative Phase: To Identify Depressed Elderly Persons' Subjective Experiences of the Healthcare System}

The outcomes of the implementation research, i.e. the improvements in patient well-being in terms of acceptability, were examined at individual level using the concepts of satisfaction, function and symptomatology [14]. The initial analysis of the interview data highlighted the importance of patients' need to participate in the care process [6]. Exploring the patients' experiences of acceptability or the "what" is acceptable showed that improved self-management is essential for empowering depressed elderly persons [7]. In the first exploratory study, elderly patients' lived experiences of depression and self-management were investigated. We found that patients' experiences of satisfaction referred to relationships and togetherness [7]. Being depressed can imply a lack of self-management, resulting in a sense of estrangement on one hand and togetherness on the other. In regard to patient-centeredness it includes respect for the patient's individuality, values, need for information and social relationships. However, some relationships were not nurturing and aroused a sense of obligation rather than commitment, involvement and understanding [7].

Critical evaluation of dimensions of healthcare delivery revealed that the burden of illness was not reduced [22]. We found that there was lack of trust in the community healthcare system's commitment to bringing about effectiveness and change. Patients should be safe, yet some of them did not know how to enter into contact with responsible staff. The lack of continuity of care and effectiveness of the healthcare system resulted in ineffective care. In terms of patient-centeredness, individual patients' did not participate in decisions about their care and treatment, their values were not respected nor were their specific needs fully met. Evaluation of shared decision-making in the care of depressed elderly persons after implementation of the CCM was intended to prevent the violation of human dignity by changing attitudes, increase understanding by clarifying the care manager's role and responsibility as well as preserve depressed elderly persons' autonomy [23]. It was also clear that timeliness of care, which involves reducing waiting times and delays for both patients and healthcare professionals, was not achieved. Care efficiency and the reduction of costs were not taken into account. The relation between patients' experiences of physical health problems and service outcomes such as safety revealed the necessity of understanding of patients' experiences of living with stigma [8]. The patients wished to be taken seriously and reported that they had the impression that healthcare professionals ignored their physical problems. They longed to be heard and believed when reporting their health problems to staff. They were also uncertain about whether the pain was physical or mental [8].

\subsection{Phase 2: Implementation of the CCM-Barriers to and Facilitators of Success}

Successful change was found on individual and group/team levels. Barriers at group/team level were lack of cooperation and coordination as well as limited responsibilities for shared decision making. A barrier at staff level was lack of knowledge of evidence-based care, which precluded use of the best scientific and clinical information.

We explored the staff member's experiences of acceptability or the "what" is acceptable as an outcome of the implementation process [24]. We found a lack of effective team leadership in the community, the need to change the delivery system, and enhancing self-management support for depressed elderly persons and promote the participation of their family members. The second paper followed-up healthcare professionals one year after implementation who had attended education about the CCM. It reveals problems ensuring a pathway to the top level of the organizations, the necessity for effective leadership from senior managers, as well as the need to formalize collaboration and increase self-management [24].

Ethical dilemmas involved in promoting self-management among depressed older persons emerged at the end of the first project and were related to the healthcare professionals' struggle to ensure reliable transfer of information and balance autonomy, care and dignity as well as to differences in the understanding of responsibility [22] Another problem was the lack of engagement on the part of and trust between the various professional categories based in the community, which could have serious implications for patient dignity as well as safety. Thus it is necessary to increase efficiency of care across disciplines and roles. It is also appropriate to enhance knowledge sharing. There was little change in the area acceptability from the patient perspective. Their experiences of living with stigma, being afraid and helpless, dependent on others, feelings of isolation and hopelessness as well as lack of access to care were not improved. However, two aspects should be emphasised. First, a success factor was the self-management component. The support provided had positive effects on the patients' 
confidence to manage everyday life [7].

Focusing on the self-management component concerns the potential to improve by effective leadership. Second, how to manage information and information systems changed due to awareness of the clear responsibility between the team members [24] [25].

\subsection{Phase 3: Evaluation: Evaluating the Quality of Care Provided in Relation to the CCM Components}

Acceptability of the CCM implementation in terms of patients' outcomes, their needs and support was partly achieved by changes in self-management support. Effective leadership plays an important role in quality of care and patient safety. The leader's awareness of the need to implement changes in practice by using guiding principles for the design and feasibility of safe care were highlighted [12] [26]. In addition, cooperation is necessary to ensure safety. The challenges involved in redesigning the delivery system and interdisciplinary team cooperation results in effective teams and team work [12]. It was concluded that a collaborative approach can facilitate self-development and management. Special focus should be placed on ensuring evidence-based knowledge to strengthen the theory base of healthcare for depressed elderly persons and improving their health outcomes. The primary aim of the paper evaluating evidence-based implementation strategies for improving the care of depressed elderly persons argues for the use of evidence-based knowledge [27]. The implementation of the CCM partly improved decision support, providing optimal care at the right time [24]. Decision-making based on evidence-based knowledge is influenced by many factors such as leadership, working climate, user participation, work load, resources, flexibility and individual factors. In addition, Holm and Severinsson [28] revealed that depressed older persons desire a guardian and wish to be independent despite being dependent.

\section{Discussion}

We applied Proctor et al.'s [14] key concepts; acceptability appropriateness, feasibility, and fidelity to refine, elaborate and synthesise our understanding of the implementation outcomes. The intervention was based on the $\mathrm{CCM}$ theory. We combined literature reviews, qualitative interview techniques including face-to-face semistructured interviews and focus groups. A purposive sampling strategy was used to recruit patients and professionals for this four year project. The strength of this study is the opportunity to report experiences of depression by means of content and hermeneutic analysis. A limitation is transferability [29] as the results are only valid for the study group, which comprised depressed elderly persons.

The main results from this study indicate that understanding and evaluating the implementation of complex interventions in practice require skilled healthcare leaders to coordinate the change process. The effectiveness of the intervention that influenced the implementation outcomes was characterized as: 1) the individual healthcare professionals' knowledge, attitudes, performance and ability to improve professional practice after implementation of the CCM; 2) patient factors, i.e. their needs and knowledge as well as ability to manage daily life; 3) organizational factor such as the management of teams and available resources for collaboration and cooperation in different settings. These factors are in accordance with research by Grol [30] who emphasized the social context of care delivery such as the reactions of patients, professionals and authorities as well as the organisational context, climate structures and available resources. The impact of social and political factors was not specifically explored. However, changed care processes to improve the management of depression imply that care should be seen as multidisciplinary collaboration and redesigned when necessary. Traditional boundaries between disciplines are less relevant [30]. This is in accordance with Wagner [31], who stated that effective chronic care such as for depression relies on multidisciplinary teams. Our studies indicate that reciprocity in relationships, feedback from individual care providers, the use of guidelines and reorganisation of practice to better meet patients' needs are of importance. Thus, integrated multidisciplinary management of depression can be more effective if the components (assessment and treatment) of high quality of care are defined by evidence based clinical management and self-management support. According to Wagner [31], educational and supportive interventions directed at helping patients to change risky behaviours or become better self-managers improve outcomes across a range of chronic illnesses. This project provides evidence of the way in which the CCM improved healthcare professionals' practice. Knowledge and information were considerable contributing factors to quality of life. Changing the organization of patient care contributed to improved patient outcomes such as better self-management, and a higher level of participation in informed decisions about treatment. This is in accordance with the review 
on quality improvement strategies by Wensing et al. [32], who found that patient outcomes were improved by multidisciplinary teams and integrated care services. However, our findings underscore results from studies that indicating that depressed elderly patients are dissatisfied due to dependency on others, isolation and hopelessness as well as lack of access to care [8]. The barriers and facilitators were identified at the beginning of the research process as recommended by Cheater et al. [33] in order to tailor the intervention: the assess the effectiveness of implementation strategies to barriers to change were; lack of organizational, administrative and professional ability to implement the CCM; lack of clarity pertaining to the care managers' responsibility for promoting the patient's self-management ability. These barriers are in accordance with those classified by the Cochrane Effective Practice and Organisation of Care Group has classified. In terms of the facilitators of success, two themes emerged: leadership support and vision; redesigning the delivery system [18].

\section{Recommendations}

The present results from the published twenty studies and forthcoming scientific publications reveal that more efforts are needed to understand and improve the care of depressed elderly patients. Several aspects must be developed in order to meet the needs of such individuals in order to increase their self-management. The research area of patient safety should be the outcome variable and include aspects such as; participation, dignity, daily activity, survival and autonomy. Although guidelines and regulations for improved care exist, healthcare professionals need education in order to understand them and act accordingly. Better information is required about how to act to ensure patient safety and enhance the quality of care.

\section{Conclusion}

An improved understanding of the implementation outcomes will have an impact on best practice for depressed elderly persons and dissemination purposes. However, the patients' needs and desire are not always met. A shift in policy towards user involvement is important. Quality management and highly action-oriented involvement are necessary in implementation research. These will also affect the professional development of interdisciplinary teams as well as constitute a basis for further research on understanding and improving the care of depressed elderly individuals.

\section{Acknowledgements}

We want to express our appreciation to the patients and staff that participated in the studies. We would also like to thank to Gullvi Nilsson and Monique Federsel for reviewing the English language. This is a report of the project entitled "Chronic Disease Management-Implementation and coordination of healthcare systems for depressed elderly persons”, funded by the Research Council of Norway (Grant No. 204238/V50) from 2010-2014.

\section{Contributors}

The study was designed and the protocol written by ES and ALH. ES coordinated the research. ALH was responsible for the data collection, which took the form of interviews and electronic reviews. ALH and ES participated in the data analysis and interpretation. The report was written by ES and ALH.

\section{References}

[1] World Health Organisation (2002) Innovative Care for Chronic Conditions: Building Blocks for Action. WHO, Geneva.

[2] Wagner, E., Austin, B., Davis, C., Hindmarsh, M., Schaefer, J. and Bonomi, A. (2001) Improving Chronic Illness Care: Translating Evidence into Action. Health Affairs, 20, 64-78. http://dx.doi.org/10.1377/hlthaff.20.6.64

[3] World Health Organisation (2005) Mental Health Action Plan for Europe, Facing the Challenges, Building Solutions. WHO European Ministerial Conference on Mental Health, Helsinki, 12-15 January 2005. http://apps.who.int/iris/handle/10665/107627

[4] World Health Organisation (2008) Caring for People with Chronic Conditions: A Health System Perspective. http://apps.who.int/iris/bitstream/10665/112830/1/9789241506793 eng.pdf?ua=1

[5] World Health Organisation (2013) Mental Health Action Plan (2013-2020). WHO Document Production Services, 
Geneva. http://apps.who.int/iris/bitstream/10665/89966/1/9789241506021 eng.pdf?ua=1

[6] Lyberg, A., Holm, A.L., Lassenius, E., Berggren, I. and Severinsson, E. (2013) Older Persons' Experiences of Depressive Ill-Health and Family Support. Nursing Research and Practice, 2013. http://dx.doi.org/10.1155/2013/837529

[7] Holm, A.L., Lyberg, A., Lassenius, E., Berggren, I. and Severinsson, E. (2013) Older Persons' Lived Experiences of Depression and Self-Management. Issues in Mental Health Nursing, 10, 757-764. http://dx.doi.org/10.3109/01612840.2013.809829

[8] Holm, A.L., Lyberg, A. and Severinsson, E. (2014) Living with Stigma: Depressed Elderly Persons' Experiences of Physical Health Problems. Nursing Research and Practice, 2014. http://dx.doi.org/10.1155/2014/527920

[9] Holm, A.L. and Severinsson, E. (2014) Surviving Depressive Ill-Health: A Qualitative Systematic Review of Older Persons' Narratives. Nursing and Health Sciences, 16, 131-140. http://dx.doi.org/10.1111/nhs.12071

[10] Bodenheimer, T., War, E.H. and Grumbach, K. (2002) Improving Primary Care for Patients with Chronic Illness. The chronic care model. JAMA, 288, 1775-1779. http://dx.doi.org/10.1001/jama.288.14.1775

[11] Bodenheimer, T., Wagner, E.H. and Grumbach, K. (2002) Improving Primary Care for Patients with Chronic Illness. The Chronic Care Model, Part 2. Journal of the American Medical Association, 2, 1909-1914. http://dx.doi.org/10.1001/jama.288.15.1909

[12] Severinsson, E. and Holm, A.L. (2014) Chronic Disease Management-Implementation and Coordination of Healthcare Systems for Depressed Elderly Persons. Issues of Mental Health. (Pub ahead of Print)

[13] Fixsen, D.L., Naoom, S.F., Blasé, K.A., Friedman, R.M. and Wallace, F. (2005) Implementation Research: A Synthesis of the Literature (FMHI\#231). University of South Florida, Louis de la Parte Florida Mental Health Institute, The National Implementation Research Network, Tampa.

[14] Proctor, E., Silmere, H., Raghavan, R., Hovmand, P., Aarons, G., Bunger, A., Griffey, R. and Hensley, M. (2010) Outcomes for Implementation Research. Conceptual Distinctions, Measurement Challenges, and Research Agenda. Administration and Policy in Mental Health Services Research, 38, 65-76. http://dx.doi.org/10.1007/s10488-010-0319-7

[15] Institute of Medicine Committee on Crossing the Quality Chasm (2006) Adaption to Mental Health and Addictive Disorder: Improving the Quality of Health Care for Mental and Substance-Use Conditions. Institute of Medicine, National Academies Press, Washington DC.

[16] Berwick, D.M. (2002) A User's Manual for the IOM's 'Quality Chasm' Report. Health Affairs, 21, 80-90. http://dx.doi.org/10.1377/hlthaff.21.3.80

[17] Proctor, E., Landsverk, J., Aarons, G., Chambers, D., Glisson, C. and Mittman, B.V. (2009) Implementation Research in Mental Health Services: An Emerging Science with Conceptual, Methodological, and Training Challenges. Administration Policy Mental Health, 36.

[18] Holm, A.L. and Severinsson, E. (2012) Chronic Care Model for Management of Depression: Synthesis of Barriers to, and Facilitators of, Success. International Journal of Mental Health Nursing, 21, 513-523. http://dx.doi.org/10.1111/j.1447-0349.2012.00827.x

[19] Holm, A.L. and Severinsson, E. (2014) Effective Nursing Leadership of Older Persons in the Community. Journal of Nursing Management, 22, 211-224. http://dx.doi.org/10.1111/jonm.12076

[20] Declaration of Helsinki. World Medical Association. http://www.wma.net/e/ethicsunit/helsinki.htm

[21] Liamputtong, P. (2007) Researching the Vulnerable. Sage Publisher, London.

[22] Holm, A.L. and Severinsson, E. (2014) Reflection on the Ethical Dilemmas Involved in Promoting Self-Management. Nursing Ethics, 21, 402-413. http://dx.doi.org/10.1177/0969733013500806

[23] Holm, A.L., Lyberg, A., Berggren, I. and Severinsson, E. (2014) The Meaning of Participation in Shared Decision-Making after Implementation of Chronic Care Model (CCM)-An Evaluative Approach. Open Journal of Nursing, 4, 683-694. http://dx.doi.org/10.4236/ojn.2014.410073

[24] Holm, A.L. and Severinsson, E. (2013) Interdisciplinary Team Collaboration during Discharge of Depressed Older Persons. Nursing Research \& Practice, 2013. http://dx.doi.org/10.1155/2013/794743

[25] Holm, A.L. and Severinsson, E. (2014) Perceptions of the Need for Improvements in Healthcare after Implementation of Chronic Disease Management. Nursing \& Health Sciences. (E-pub ahead of Print) http://dx.doi.org/10.1111/nhs.12136

[26] Severinsson, E. (2014) Effectiveness and Implementation of Patient Safety Care. Journal of Nursing Management, 22, 823-824. http://dx.doi.org/10.1111/jonm.12263

[27] Severinsson, E. and Holm, A.L. (2014) Implementation Strategies for Improving Care of Depressed Elderly Personssummary of an International Workshop. Open Journal of Nursing, 4, 715-723.

http://dx.doi.org/10.4236/ojn.2014.411076 
[28] Holm, A.L., Lyberg, A., Berggren, I. and Severinsson, E. (2014) Social Capital and Depressive Ill Health-An Evaluative Approach to the Implementation of the Chronic Care Model (CCM). Open Journal of Nursing, 4, 683-694.

[29] Elo, S., Kääriänen, M., Kanste, O., Pölkki, T., Utrianien, K. and Kyngärs, H. (2014) Qualitative Content Analysis: A Focus on Trustworthiness. Sage Open, Jan-Mar, 1-10.

[30] Grol, R., Bosch, M., Hulscheir, M., Eccles, M. and Wensing, M. (2007) Planning and Studying Improvement in Patient Care: The Use of Theoretical Perspectives. The Milbank Quarterly, 85, 93-138. http://dx.doi.org/10.1111/j.1468-0009.2007.00478.x

[31] Wagner, E.H. (2000) The Role of Patient Care Teams in Chronic Disease Management. British Medical Journal, 320, 569-572. http://dx.doi.org/10.1136/bmj.320.7234.569

[32] Wensing, M., Wollersheim, H. and Grol, R. (2006) Organizational Interventions to Implement Improvements in Patient Care: A Structured Review of Reviews. Implementation Science, 1, 2. http://dx.doi.org/10.1186/1748-5908-1-2 http://www.implementationscience.com/content/1/1/2.

[33] Cheater, F., Baker, R., Gillies, C., Hearnshaw, H., Flottorp, S., Robertson, N., Shaw, E.J. and Oxman, A.D. (2009) Tailored Interventions to Overcome Identified Barriers to Change: Effects on Professional Practice and Health Care Outcome. The Cochrane Library, Issue 4. http://www.thecochranelibrary.com 
Scientific Research Publishing (SCIRP) is one of the largest Open Access journal publishers. It is currently publishing more than 200 open access, online, peer-reviewed journals covering a wide range of academic disciplines. SCIRP serves the worldwide academic communities and contributes to the progress and application of science with its publication.

Other selected journals from SCIRP are listed as below. Submit your manuscript to us via either submit@scirp.org or Online Submission Portal.
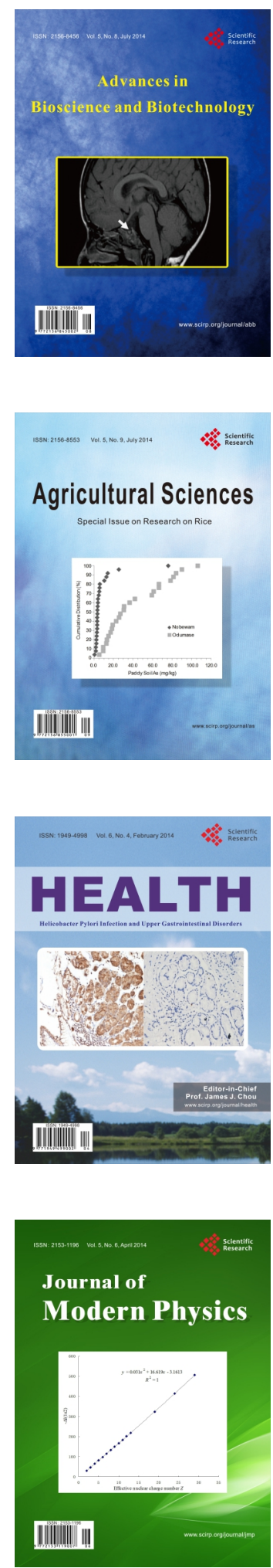
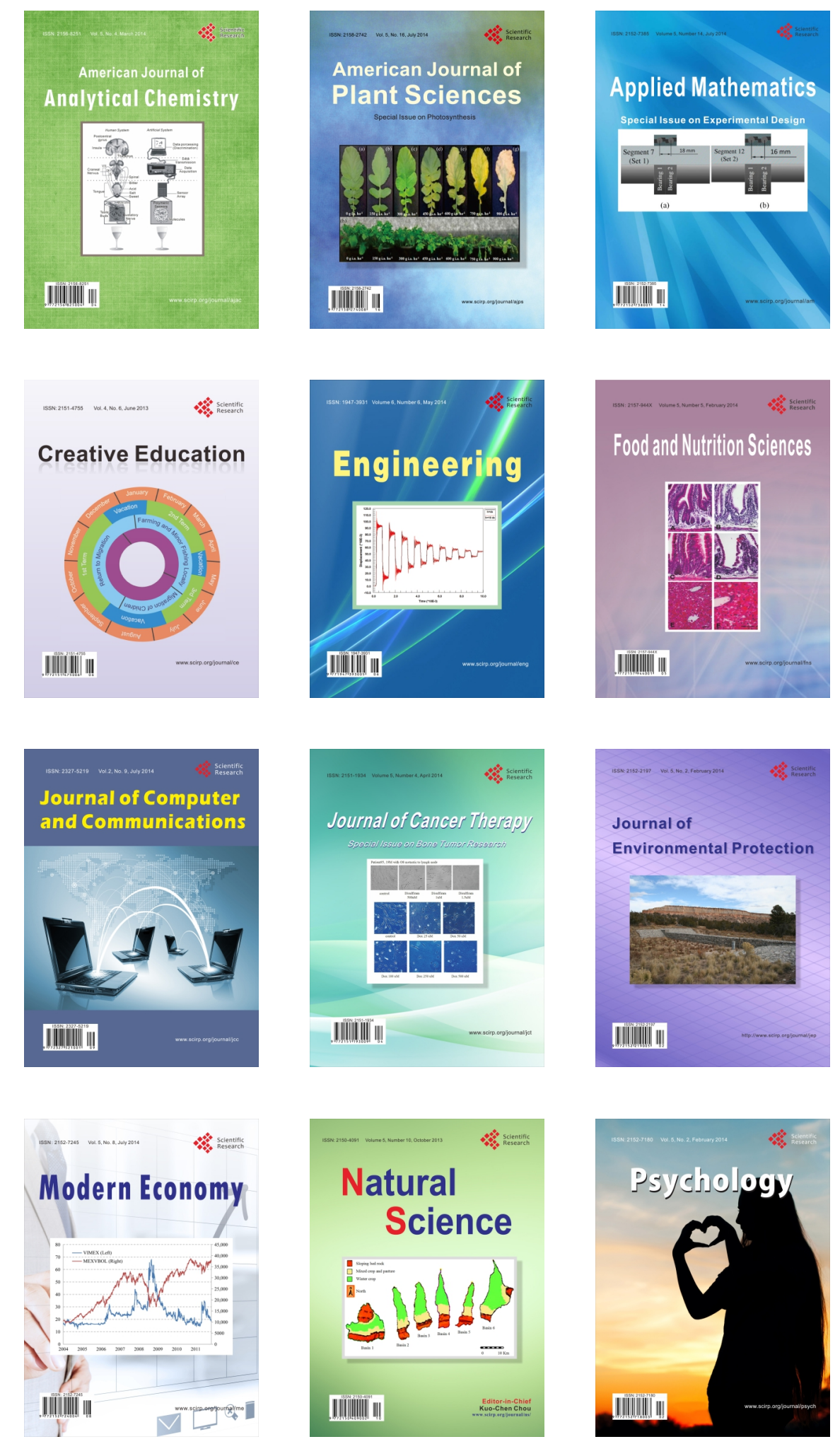